\title{
O SUJEITO INDÍGENA TERENA: ENTRE A TUTELA E O PROTAGONISMO
}

\author{
Nair Cristina Carlos de Medeiros*
}

\begin{abstract}
RESUMO: Este artigo pretende problematizar dizeres hegemônicos que atravessam o discurso de sujeitos Terena do Mato Grosso do Sul sobre a tutela indígena e verificar os modos como se dão os processos de ressignificação desses discursos. Partimos da hipótese de que esses sujeitos fazem emergir outros sentidos aos discursos instituídos sobre a identidade indígena, promovendo resistências às certezas que os significam. A materialidade linguística analisada compõe-se de recortes discursivos de postagens publicadas na rede social Facebook. Nosso referencial teórico é a Análise do discurso de linha francesa e viés foucaultiano, além de contribuições de autores do Pensamento Decolonial.
\end{abstract}

RESUMEN: Este artículo tiene la intención de problematizar los dichos hegemónicos que atraviesan el discurso de los sujetos Terena de Mato Grosso do Sul sobre la tutela indígena y verificar las formas en que se dan los procesos de resignificación de estos dichos. Partimos de la hipótesis de que estos sujetos aportan otros significados a los discursos establecidos sobre la identidad indígena, construyendo resistencias frente a los hechos que les dan significado. La materialidad lingüística estudiada es compuesta de extractos de publicaciones subidas en la red social Facebook. Nuestro marco teórico es el Análisis del discurso de matriz francesa y el sesgo foucaultiano, así como contribuciones de los autores de Pensamiento Decolonial.

PALAVRAS-CHAVE: Protagonismo indígena. Povos Terena. Identidade indígena.

PALABRAS-CLAVE: Protagonismo indígena. Pueblos Terena. Identidad indígena.

\section{Considerações iniciais}

A tutela indigenista tem sua "origem" nas formas como a colonização se impôs aos povos indígenas. A ideia de raça foi fundamental para que os agentes colonizadores categorizassem esses povos, atribuindo-lhes distinções e estatuto de inferioridade, permitindo o estabelecimento de hierarquias e a naturalização das desigualdades sociais e legitimando o processo de colonização (QUIJANO, 2005). Situados em um grau inferior da evolução, o indígena precisaria de um protetor, de alguém que o representasse e atuasse como seu provedor e que o auxiliasse em sua integração à sociedade dos brancos. Instituise a partir daí um processo de assimilação religiosa, econômica, e cultural ancorado por uma rede de sentidos que significam esses povos negativamente. Dessa forma, a visão estereotipada do indígena como ser incapaz de autogoverno passa a ser institucionalizada e os "silvícolas", assim denominados no Código Civil de 1916, "ficarão sujeitos ao regime tutelar, estabelecido em leis e regulamentos especiais, o qual cessará à medida que forem adaptados à civilização do País" (BRASIL, 1916, p.1).

A partir da década de 1970, tem início um processo de mobilizações de povos indígenas em várias regiões do país que culminará na primeira mudança efetiva da concepção de

INTERLETRAS, ISSN No 1807-1597. V. 9, Edição número 34. Outubro, 2021/ Março de 2022- p

Dossiê: Estudos de indigenismo, negritude e miscigenação: o (des)cobrimento, colonização e o agora(?) . 
tutela, quando eles têm assegurado, na Constituição de 1988, o direito à sua própria cultura, às terras tradicionalmente ocupadas, impondo à União o dever de zelar pelo cumprimento desses direitos. O documento dedica um capítulo inteiro aos índios ${ }^{1}$ e o artigo 231 traz em seu texto o reconhecimento de suas organizações sociais, seus costumes, suas línguas, crenças e tradições, e os direitos originários sobre as terras que tradicionalmente ocupam (CUNHA, 2008). No texto da lei, a perspectiva integracionista do Estado parece ser superada com o reconhecimento da pluralidade cultural. As diferentes assembleias, encontros, mesas de discussões apresentaram novas possibilidades de atuação e foram construindo uma mentalidade nova nas lideranças indígenas que delas participavam, possibilitando a emersão de novos posicionamentos, novas práticas discursivas.

Inicia-se, assim, um longo processo de mudança do paradigma integracionista, homogeneizador e tutelar para um paradigma que compreende os povos originários como sujeitos de direito, o que promoverá consequências fundamentais para a atualização e afirmação de suas identidades étnicas. As implicações dessa constituição jurídica remetem à construção social e política de um novo estatuto para esses povos e trazem para a cena o protagonismo indígena - entendido aqui como a afirmação de seus costumes, tradições, concepções de mundo, enfim, de suas identidades - e a necessidade de romper com as relações de tutela e assumir-se como sujeito da própria história.

É nesta configuração em que, ao mesmo tempo, há um dizer que representa o "índio" como incapaz, objeto a ser tutelado pelo branco e outros dizeres que buscam produzir discursos outros, ressignificar e reformular suas identidades, que buscamos problematizar os discursos produzidos por esses sujeitos indígenas Terena na rede social Facebook. Nossa referência teórica é a Análise do Discurso de linha francesa a partir dos conceitos de sujeito, memória, interdiscurso e formações discursivas propostos por Pêcheux (1988), da formulação do conceito de formações discursivas realizada por Foucault (1986) e da problematização de noções como identidade, processos identitários e identificações realizadas por Hall $(2006,2010)$ e Coracini (2003). Nossa hipótese é a de que esses sujeitos usam a rede social Facebook para fazer emergir outros sentidos aos discursos instituídos sobre a identidade indígena, promovendo resistências às certezas que os categorizam negativamente.

\section{O sujeito, as identificações e as relações de poder}

1 Neste trabalho, usamos indistintamente os termos “índio" e "indígena”, seguindo a orientação do indígena Baniwá, Gersem Luciano (2006, p. 30), que afirma que, nos anos 70, período da consolidação do Movimento Indígena no Brasil, os povos indígenas perceberam que era importante "manter, aceitar e promover a denominação genérica de índio ou indígena, como uma identidade que une, articula, visibiliza e fortalece todos os povos originários do atual território brasileiro.

INTERLETRAS, ISSN No 1807-1597. V. 9, Edição número 34. Outubro, 2021/ Março de 2022- p

Dossiê: Estudos de indigenismo, negritude e miscigenação: o (des)cobrimento, colonização e o agora(?) . 
A perspectiva discursiva que adotamos opera com a concepção de um sujeito descentrado, que tem a ilusão de ser a fonte do sentido e carrega consigo marcas do social, do ideológico e do histórico. Nessa compreensão, o sujeito é dividido na/pela linguagem, perpassado pelo inconsciente, atravessado pela história e inscrito em uma determinada formação discursiva com a qual ele se identifica e que o constitui. Ao (se)dizer, esse sujeito traz fios discursivos, já-ditos, provenientes de várias regiões do discurso: do inconsciente, da memória discursiva, do contexto sócio-histórico em que se situa, enfim, do interdiscurso. Há, assim, a presença de um ou de outros no discurso, há uma multiplicidade de vozes, há a heterogeneidade do discurso que, de acordo com AuthierRevuz (1998), manifesta-se na materialidade linguística. O sujeito fala e é falado ao mesmo tempo, pois, através do dito, outros dizeres são ditos.

Dessa forma, os sujeitos não são a origem do discurso e, sim, efeitos discursivos. O sujeito é um efeito sujeito do imenso desconhecido de sua vida psíquica, das estruturas inconscientes que o determinam (Lacan), das práticas sociais e discursivas que os constituem (Marx), das estruturas existentes no sistema da língua (Saussure) e das estruturas de poder que constituem os regimes de verdade (Foucault) (HALL, 2010). Em oposição à compreensão de que o sujeito pensa, conhece e sabe o que diz, nessa perspectiva, o discurso é que determinará as posições ocupadas pelos sujeitos (FOUCAULT, 2008). O sujeito, nesta representação, não é produtor de saberes, é sim um produto dos saberes, "não é um produtor, mas é produzido no interior de saberes" (VEIGA-NETO, 2003, p. 44). Assim, o sujeito assume diferentes posições construídas socialmente e que se modificam, transformam e se estabilizam nas mudanças históricas.

Em conformidade com Hall (2010, p. 111), assumimos a identidade como o ponto de encontro entre os discursos e práticas que tentam nos convocar "para que assumamos nossos lugares como os sujeitos sociais de discursos particulares e os processos que produzem subjetividades, que nos constroem como sujeitos aos quais se pode falar". A identidade e os processos identitários tornam-se, assim, um conceito fundamental e estratégico, pois embora vivencie a própria identidade como unificada, o sujeito encontrase partido, cindido e a identidade, portanto, não implica um núcleo estável, permanecendo sempre incompleta, sempre em processo, sempre em formação (CORACINI, 2003), Nesta perspectiva, a identidade vista como unidade, inteireza e estabilidade é uma fantasia, o que nos leva a compreendê-la como processos de identificações nunca finalizados

Assumimos ainda, como pressuposto teórico, contribuições de autores do Pensamento Decolonial que buscam interpretar, deslocar e subverter a perspectiva colonizadora e geradora de estereótipos dos discursos coloniais. De acordo com esses teóricos, o fim do colonialismo não significou o fim da colonialidade, uma vez que a principal característica desse processo foi a dominação cultural, que determinou os modos de produzir e expressar a realidade via conhecimento. Com o fim da dominação política do sistema colonial, a colonialidade do poder torna-se extremamente bem sucedida, pois a "cultura

INTERLETRAS, ISSN No 1807-1597. V. 9, Edição número 34. Outubro, 2021/ Março de 2022- p

Dossiê: Estudos de indigenismo, negritude e miscigenação: o (des)cobrimento, colonização e o agora(?) . 
europeia se converteu, ademas, en una seducción ao colonizado: daba acceso al poder". A elite da colônia vê no modelo europeu uma forma de superação do próprio colonialismo, para "alcançar os mesmos benefícios materiais e o mesmo poder que os europeus; para conquistar a natureza" (QUIJANO, 1992, p. 13).

A colonialidade do poder é, portanto, um padrão colonial de poder que produziu discriminações sociais que "posteriormente foram codificadas em 'raciais', 'étnicas', 'antropológicas' ou 'nacionais, segundo o momento, os agentes e as populações implicadas"” (QUIJANO, 1992, p. 12). É nesta relação de poder que os povos indígenas, primeiros a serem conquistados e dominados, foram constituídos discursivamente e naturalizados como inferiores, condição que, como sabemos, permaneceu mesmo quando o colonialismo foi superado e os países da América se tornaram "independentes". Entre nós, o fim do colonialismo não significou o fim da colonialidade. Quijano (1992) propõe, assim, a descolonização epistemológica como alternativa para liberar a produção do conhecimento que se apoie na diversidade e na heterogeneidade histórica de todas as sociedades e dar alternativas a todas as gentes de optar entre as diversas orientações culturais com liberdade para produzir, criticar e estabelecer trocas culturais.

A espoliação colonial, consequência do "projeto de modernidade", é legitimada por um imaginário que estabelece que as comunidades indígenas ocupem o mais baixo "estágio na escala de desenvolvimento humano": são selvagens, bárbaros, em "estado de natureza". Nessa passagem da ignorância à maioridade, a sociedade europeia já havia alcançado o último estágio, o estágio do "outro absoluto do primeiro", onde "reina a civilidade, o Estado de direito, o cultivo da ciência e das artes". Era necessário que os índios deixassem de ser "selvagens" e alçassem ao "estágio mais avançado da espécie humana", transformando-se em entes colonizados. Daí a necessária "invenção do outro" à nossa imagem, conforme nossa semelhança, projeto que se inicia no período colonial com uma política indigenista que vinculava o desenvolvimento das populações indígenas à sua integração com o resto da sociedade (CASTRO-GÓMEZ, 2005).

Conforme aponta Quijano (2005), a ideia de "raça", para se referir às diferenças fenotípicas entre "índios" e conquistadores, sustenta a visão de que existem diferenças de natureza biológica e sustenta as relações de poder no capitalismo mundial/moderno. A partir dessa ideia, estrutura-se uma rede de sentidos - incapaz, infantil, ingênuo, primitivo, selvagem - que legitima a necessidade de tutela do Estado, em relação ao índio. Estando na infância da humanidade, o índio precisa de um protetor, de alguém que o represente e atue como seu provedor e que o auxilie a se integrar à sociedade dos brancos. Estas práticas de imposição da colonização aos povos indígenas dão início e sustentam a tutela indigenista; durante o século XVI, predomina a afirmação de que os povos indígenas não pertenciam à categoria de humanos; posteriormente, entre os séculos XVIII e XIX, admitiu-se e reconheceu-se a humanidade desses povos, mas prevaleceu a ideia de que pertenciam a uma categoria inferior de raça humana que deveria ser "aprimorada" pelos colonizadores.

INTERLETRAS, ISSN No 1807-1597. V. 9, Edição número 34. Outubro, 2021/ Março de 2022- p

Dossiê: Estudos de indigenismo, negritude e miscigenação: o (des)cobrimento, colonização e o agora(?) . 
A história dos povos indígenas brasileiros, incluindo-se a história dos povos Terena, mostra que as ações dos diferentes órgãos do Estado, legitimadas por esse discurso de "aperfeiçoamento" e da necessidade de tutela, foram no sentido de excluir os índios dos espaços públicos e privados. Inicialmente, as ações tiveram como objetivo a imposição da cultura pela evangelização, visando à apropriação da mão de obra indígena. A escola, dispositivo disciplinar legitimado pela escrita, foi utilizada como espaço de imposição da cultura europeia e da alfabetização na língua oficial, desempenhando um papel fundamental na negação das identidades culturais desses povos.

Com os direitos legalmente amparados na Carta Magna, os movimentos de resistência reivindicando seu cumprimento se intensificaram, as comunidades lutam para que o Estado e a sociedade brasileira respeitem seus direitos e os povos indígenas vêm se assumindo cada vez mais como protagonistas de suas vidas. A identificação e legalização das terras tradicionais, o aumento da participação na construção de políticas públicas voltadas para seus interesses, além da participação direta nas políticas partidárias, inclusive com candidatura de indígenas para diferentes cargos do poder legislativo, são exemplos de bandeiras políticas dos povos indígenas, entre eles os povos Terena, nos últimos anos. "Chegou o momento do índio não só requerer direitos, mas responsabilidade, coparticipação", afirma Marcos Terena em Conferência realizada em junho de $2006^{2}$.

\section{O sujeito indígena Terena: entre a tutela, a autonomia e o protagonismo}

Os povos Terena constituem a segunda maior população indígena de Mato Grosso do Sul, contando atualmente com aproximadamente 23.000 pessoas localizadas vivendo em um território fragmentado e espalhado em nove Terras Indígenas de diferentes municípios do Mato Grosso do Sul (CARDOSO, 2011). Participam ativamente do cotidiano da vida sul mato-grossense, seja nas relações de comércio informal pelas ruas das cidades onde residem, seja na realização de trabalho temporário informal nas fazendas da região. Possuem uma trajetória marcada, por um lado, pela rejeição e pela negação da sociedade envolvente, por outro lado pelas reivindicações de seus territórios originais (VARGAS, 2011).

Assim como os demais povos indígenas, os Terena têm se destacado na busca pela autonomia em diferentes áreas de atuação, constituindo uma mentalidade nova nas lideranças e surgindo, a partir daí, "um novo campo enunciativo e novas configurações à prática discursiva indígena" (GUERRA, 2015, p. 99). Emergem, assim, novos regimes de enunciabilidade, novos enunciados, novos discursos e, portanto, novos comportamentos

2 https://memoria.ebc.com.br/agenciabrasil/noticia/2006-07-28/indigenas-sao-discriminados-de-maneirasutil-diz-marcos-terena-em-conferencia. Acesso em 27/07/2021.

INTERLETRAS, ISSN No 1807-1597. V. 9, Edição número 34. Outubro, 2021/ Março de 2022- p

Dossiê: Estudos de indigenismo, negritude e miscigenação: o (des)cobrimento, colonização e o agora(?) . 
são exigidos do sujeito indígena em relação à participação em diferentes instâncias políticas, na medida em que essas afetam suas vidas, crenças, instituições, bem-estar social e cultural. Partindo dessas considerações, passamos, assim, a investigar os processos de identificações dos sujeitos indígenas Terena, em relação aos discursos em torno das práticas tutelares. A materialidade linguística analisada compõe-se de cinco recortes discursivos (RD) de postagens publicadas no Facebook, representados pela letra $\mathrm{S}$ (sujeito), seguido pelo número de sequência da ordem com que aparecem no decorrer do texto (S1, S2...) e apresentados sob a forma de imagem, exatamente como foram publicados ${ }^{3}$.

No recorte discursivo 1, temos uma postagem de compartilhamento de uma notícia que apresenta resultado, favorável aos indígenas, do processo eleitoral no Mato Grosso do Sul. No enunciado da postagem, "União indígena com reflexo positivo!", registra-se a filiação do sujeito na rede de sentidos: a defesa da estratégia coletiva de ocupação de espaços políticos ou administrativos.

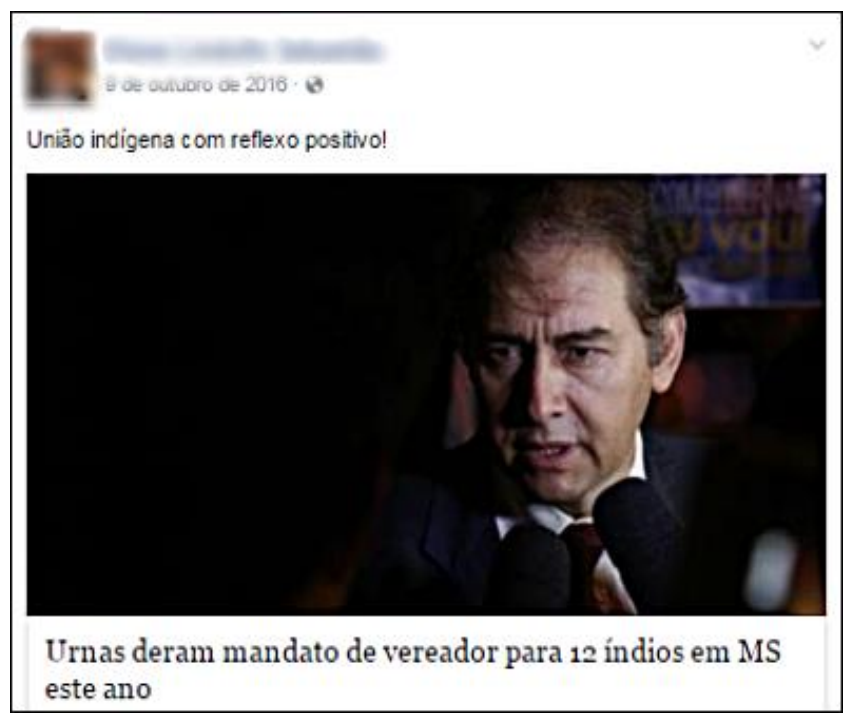

Recorte discursivo 1

Já no recorte 2, temos o compartilhamento de uma notícia, publicada no jornal Campo Grande News, que trata da indicação de um novo coordenador para a FUNAI de Campo Grande, acompanhada de um enunciado em que o sujeito chama a atenção para o fato de que, em apenas um mês, houve três indicações distintas de novos diretores. A indicação do novo coordenador regional da FUNAI, em 2016, gerou vários protestos, inclusive com

3 - Os recortes discursivos apresentados neste artigo foram capturados no Facebook, utilizando a função printscreen do computador. Apesar de termos utilizado somente postagens públicas, todos os nomes e imagens que pudessem identificar os participantes foram desfocados.

INTERLETRAS, ISSN No 1807-1597. V. 9, Edição número 34. Outubro, 2021/ Março de 2022- p

Dossiê: Estudos de indigenismo, negritude e miscigenação: o (des)cobrimento, colonização e o agora(?) . 
fechamento de ruas e ocupação de prédios públicos, organizados por lideranças indígenas do estado do Mato Grosso do Sul.

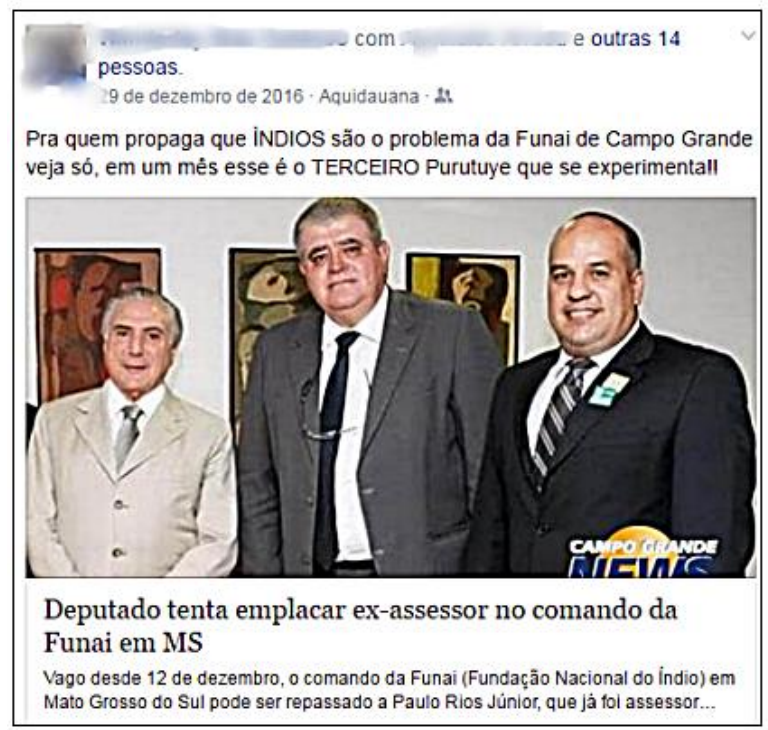

Recorte discursivo 2

O enunciado destaca o conflito existente entre os índios e o branco, os "purutuye" (designação dada ao homem branco na língua Terena), no que se refere ao comando e atuação nos órgãos públicos de defesa do índio que, para grande parte das lideranças indígenas (caciques, líderes espirituais, membros dos conselhos de aldeia, etc.), devem ser exercidos pelos próprios índios (FERREIRA, 2007). Os recortes 1 e 2 trazem à cena uma questão que é um dos eixos da luta pela autonomia dos povos indígenas: a busca pela participação efetiva nas instituições político-administrativas que lhes dizem respeito.

Embora a notícia trate das eleições para cargos legislativos municipais e os mandatos de vereadores tenham suas ações circunscritas no âmbito dos municípios, no recorte 1, S1 faz referência, por meio dos itens lexicais "união indígena", à união dos índios em todo o Estado, produzindo o sentido da existência de um movimento indígena organizado e homogêneo com projetos de dimensões mais amplas que vão além dos interesses locais de um determinado grupo ou etnia. De fato, na notícia compartilhada na postagem, um dos vereadores eleitos, Lindomar Terena, ex-presidente do Distrito Sanitário Especial Indígena de Mato Grosso do Sul (DSEI-MS) - órgão da Secretaria de Saúde Indígena (SESAI) - afirma que eleger vereadores foi uma das pautas discutidas pelas Assembleias Indígenas que determinou como estratégia política a eleição de vinte vereadores indígenas, dez no norte do estado e dez do sul (MIDIAMAX, 2016). Essa afirmação confirma a ideia de que as candidaturas indígenas fazem parte dos interesses de uma categoria mais geral, a dos "povos indígenas", e não representam interesses individuais ou de uma determinada comunidade étnica.

INTERLETRAS, ISSN No 1807-1597. V. 9, Edição número 34. Outubro, 2021/ Março de 2022- p

Dossiê: Estudos de indigenismo, negritude e miscigenação: o (des)cobrimento, colonização e o agora(?) . 
Pode-se considerar, assim, que a eleição de indígenas para os cargos político-partidários faz parte de um projeto maior, uma estratégia contra hegemônica de ruptura com as fronteiras que delimitam os espaços que os índios devem ocupar e de ruptura com discursos que representam o indígena como um ser incapaz. De acordo com Hall (2006, p. 26), a identidade emerge a partir do "[...] diálogo entre os conceitos e definições que são representados para nós pelos discursos de uma cultura e pelo nosso desejo, consciente ou inconsciente, de responder aos apelos feitos por estes significados". Ao divulgar a capacidade do índio de se unir, enfrentar as barreiras/fronteiras e ocupar espaços na esfera pública, S1 busca romper com os conceitos e definições sobre o que é ser indígena na nossa cultura e filia-se a uma outra forma de dizer e discursivizar o "ser índio", articulada a um projeto coletivo que cobra, denuncia, reivindica e ocupa espaços públicos e de enunciação. O sujeito do enunciado filia-se a um dizer que aponta para o sentido de emancipação, luta e negociação do indígena no espaço público como política de legitimação das reivindicações desses povos.

No recorte 2, S2 afirma dirigir-se a "quem propaga que ÍNDIOS são o problema da FUNAI de Campo Grande", fazendo uso do pronome relativo "quem" sem marcação de seu antecedente, materializando na cadeia de significantes a existência de um interlocutor sem determiná-lo. Afirma dirigir-se a todos aqueles que propagam que os índios são o problema da FUNAI, apontando para um "dizem por aí", um dizer outro que afirma a incapacidade do índio de atuar nas instâncias de poder que determinam as ações que lhes dizem respeito mais diretamente em oposição à capacidade dos brancos de gerir essas instituições. S2 atualiza um já-dito, sustentáculo das práticas coloniais tutelares, que propaga a superioridade do branco e a inferioridade do índio, considerado como pouco propenso às atividades intelectuais, construções, como vimos, sedimentadas em um longo processo histórico de estigmatização e opressão. Em "veja só, em um mês esse é o TERCEIRO purutuye que se experimenta", S2 desloca o dizer que declara a incapacidade do índio, destacando o fato de que o branco, sim, é incapaz de atuar na FUNAI de Campo Grande, uma vez que houve três substituições de "purutuye" em apenas um mês.

O destaque conferido aos termos "índios" e "terceiro", usados em caixa alta no texto, materializa a relação de oposição que se estabelece entre índio e "purutuye" e aponta para o confronto entre sentidos diferentes: um que constitui o índio como objeto administrado pela União, destinado a obedecer, tutelado, incapaz, problema a ser resolvido e outro que o constitui como sujeito de direito, independente, capaz de assumir de forma autônoma os rumos de sua própria história. De acordo com Ferreira (2007), os povos Terena agem deliberadamente no sentido de estimular que seus "patrícios" ocupem espaços políticos e administrativos que no passado só estavam disponíveis aos brancos. Assim, ocupar cargos de chefia e encarregados nos postos e na Administração Executiva Regional da FUNAI, lecionar nas escolas das aldeias, dirigir igrejas evangélicas e católicas, ter "representação política" nas câmaras municipais são estratégias políticas de ocupação de espaços e de afirmação da identidade para esses povos. É nesse contexto que S1 e S2 enunciam, deslocando dizeres consolidados sobre a incapacidade indígena, estabelecendo

INTERLETRAS, ISSN No 1807-1597. V. 9, Edição número 34. Outubro, 2021/ Março de 2022- p

Dossiê: Estudos de indigenismo, negritude e miscigenação: o (des)cobrimento, colonização e o agora(?) . 
confrontos e distinções entre as ações dos brancos e dos índios e, ao mesmo tempo, buscando recompor os fios da narrativa que tecem a história do que é ser índio no Mato Grosso do Sul.

No recorte discursivo 3 que segue tem-se novamente o questionamento sobre esta mesma situação de escolhas de lideranças para a FUNAI.

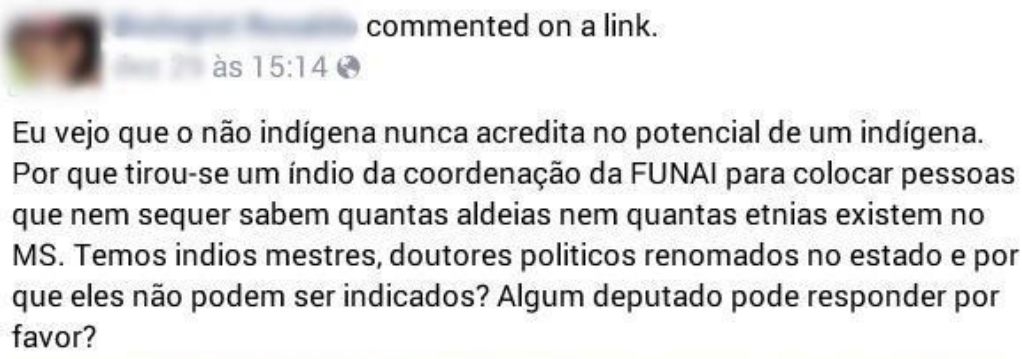

Eu vejo que o não indígena nunca acredita no potencial de um indígena. Por que tirou-se um índio da coordenação da FUNAI para colocar pessoas que nem sequer sabem quantas aldeias nem quantas etnias existem no MS. Temos indios mestres, doutores politicos renomados no estado e por que eles não podem ser indicados? Algum deputado pode responder por favor?

Recorte discursivo 3

No recorte 3, S3 atribui a indicação de um branco para a coordenação da FUNAI à crença na incapacidade do indígena. Aqui vemos novamente a comparação entre indígenas e brancos, destacando o conhecimento que o indígena tem em relação à realidade das aldeias e das etnias do MS - conhecimento que, segundo S3, o branco não tem - além da formação acadêmica e experiência política que vários possuem. Expõe-se a qualificação do indígena para opor-se a sua propalada "incapacidade" e colocar em xeque o porquê da escolha de um branco. S3 manifesta o sentimento de exclusão e discriminação vivenciado ao enunciar que, mesmo com capacidade técnica e melhor qualificação, os indígenas continuam sendo preteridos em favor do branco. De acordo com S3, mesmo com títulos acadêmicos e posições políticas "renomadas", o indígena "nunca" é aceito pelo "não indígena". "Nunca" é, de acordo com Neves (2000, p. 287), advérbio de negação que mescla ideia aspectual e temporal ao seu valor negativo. Assim, o enunciado "nunca acredita no potencial de um indígena" equivaleria a "não acredita no potencial de um indígena em tempo algum" e manifesta a histórica situação de inferioridade vivenciada pelo indígena ao longo do tempo e o desejo de ser considerado capaz, de ser o desejo do outro, ser como o outro e ser aceito pelo outro. Assim, "nunca é aceito pelo não indígena", é um enunciado registrado na memória, que atravessa os tempos, e constitui o imaginário discursivo das (im)possibilidades desse grupo marcado pelo preconceito e pela exclusão social. O sujeito enunciador do recorte lança perguntas retóricas aos deputados - por que os índios não podem ser indicados? - fazendo emergir as motivações e interesses que determinam as indicações para cargos administrativos que, na maior parte das vezes, passam ao largo das atribuições técnicas, embora se verbalize que sim. Trata-se de jogos de poder e de disputas entre grupos sociais assimetricamente situados num processo em que estão implicadas lutas mais amplas por recursos materiais e simbólicos da sociedade, processo que instaura diferenças, exclui muitos para incluir alguns outros, processo que constitui identidades.

INTERLETRAS, ISSN No 1807-1597. V. 9, Edição número 34. Outubro, 2021/ Março de 2022- p

Dossiê: Estudos de indigenismo, negritude e miscigenação: o (des)cobrimento, colonização e o agora(?) . 
Nas três sequências discursivas, há uma discursividade de afirmação da identidade indígena como sujeitos de ações políticas, capazes de organização para a disputa de posições de poder e que, através da união, elaboram suas próprias táticas para se contrapor ao regime político de tutela, ocupar espaços, antes disponíveis apenas aos "purutuye", e garantir seus interesses. Nos recortes 1 e 2, temos a afirmação da importância da representação política nas câmaras municipais para a defesa de seus interesses; no recorte 3, afirma-se a capacidade indígena ao se afirmar a incapacidade do branco, expondo a dificuldade ou falta de competência em manter um "purutuye" na função de coordenador da FUNAI. Os processos de (des)construção da tutela e da autonomia configuram, assim, relações múltiplas que apontam para a ocupação de diferentes lugares e para diferentes movimentos de identificações desses povos. No recorte discursivo 4, apresentado a seguir, destacamos mais um exemplo desta multiplicidade:

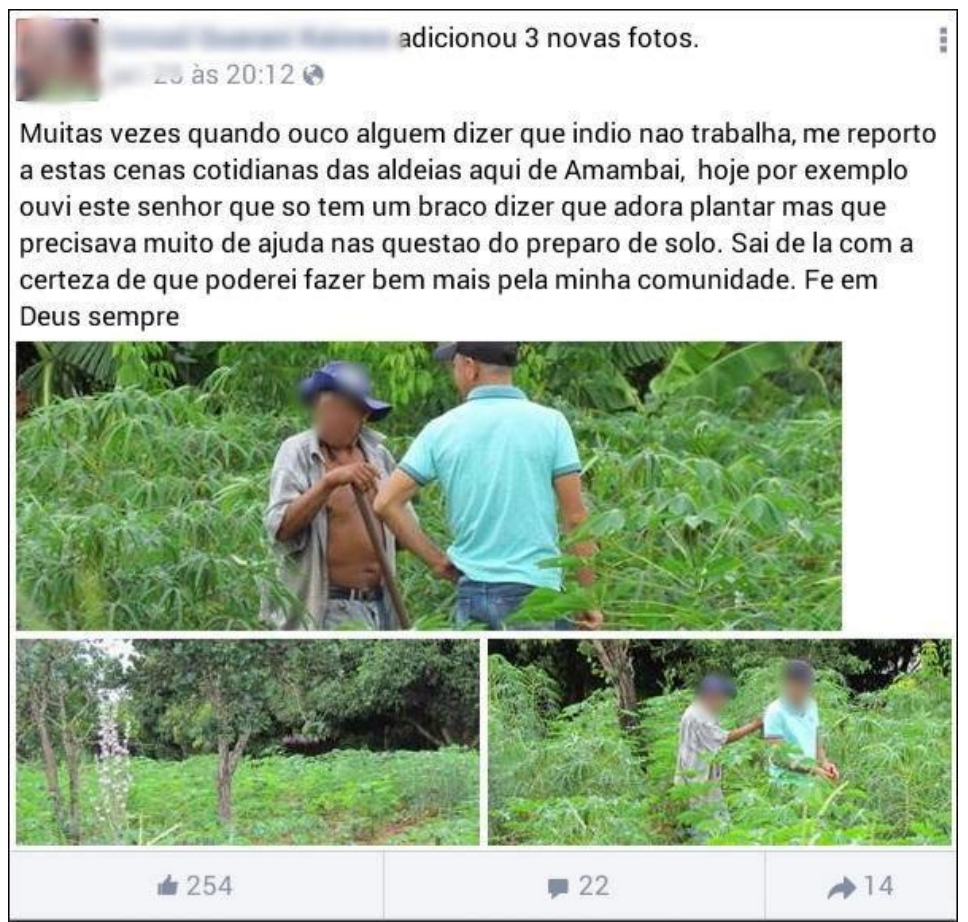

Recorte discursivo 4

O recorte 4 é composto por texto escrito e fotografias que mostram dois homens conversando em uma roça, um deles com camisa desabotoada, chapéu e enxada na mão. O texto escrito faz referência às fotografias, afirmando ser esta uma cena que faz parte do cotidiano da aldeia: pessoas trabalhadoras, capinando, arando, roçando, trabalhando a terra para o plantio. As relações dos europeus com o índio e a terra se estruturaram de forma a atender aos interesses econômicos e de conquista dos colonizadores. As relações de poder determinam o modo como nos relacionamos com o "objeto", com o território, com a natureza, que, nessa visão hegemônica da racionalidade europeia, é sempre o outro marcado de forma hierarquizada e assimétrica, de tal forma que os sujeitos e as práticas

INTERLETRAS, ISSN No 1807-1597. V. 9, Edição número 34. Outubro, 2021/ Março de 2022- p

Dossiê: Estudos de indigenismo, negritude e miscigenação: o (des)cobrimento, colonização e o agora(?). 
mostradas como diferentes são consideradas como inferiores e passíveis de se tornar objeto de conhecimento e de práticas de dominação (QUIJANO, 2005). É nesta lógica que os índios, vistos como seres inferiores, são escravizados e forçados ao trabalho e a terra é compreendida como objeto que deve ser domesticado, instalando as condições para que se produza o máximo no menor tempo possível, afinal, "tempo é dinheiro", de acordo com os interesses dos colonizadores.

O sujeito 4 faz uma contraposição entre essas "cenas cotidianas da aldeia" e a afirmação de que "índio não trabalha", afirmação muito ouvida nos tempos atuais, mas que remonta ao período da expansão colonial e à tentativa de subjugar e impor aos índios o modo de produção ocidental, através da exploração de sua mão de obra. Aqueles que resistiam à sanha de exploração e à tentativa de domesticação eram vistos como selvagens, indolentes, dando origem ao estereótipo de "índios preguiçosos", vistos como impedimento para o desenvolvimento do país. Instaura-se um conflito de visões de mundo: enquanto para os colonizadores interessava a acumulação de recursos comercializáveis através do trabalho escravo na terra, para os índios prevalecia uma relação de respeito, atentos aos seus (da terra) próprios ciclos e retirando dela apenas o necessário para sua subsistência, sem esgotar os recursos naturais.

Os índios vivem uma relação de integração com a terra, de tal forma que, em sua compreensão, são eles que pertencem à terra, diferentemente da compreensão do colonizador, do branco, do capitalismo e do agronegócio que veem a terra como sua propriedade. Nessa compreensão outra, o "trabalho" para os índios relaciona-se aos seus modos tradicionais de ocupação de seus territórios, em uma relação de interdependência baseada no conhecimento profundo e no respeito aos ciclos naturais da terra. Este embate pode ser compreendido também a partir da noção de "homens lentos" de que fala Milton Santos (2002), uma categoria criada para se referir aos homens que não fazem parte da velocidade dos processos econômicos, políticos e sociais hegemônicos. À margem dessa engrenagem, o homem lento privilegia outros vínculos, outras conexões, outras espaçotemporalidades. O que parece ser lentidão porque não atende à lógica de produção em que "tempo é dinheiro", pode ser compreendido, nesse caso, como uma temporalidade transgressora que subverte os ritmos preponderantes.

Assim, afirmar que os índios são preguiçosos, que têm muito benefícios e poucas responsabilidades perante o Estado brasileiro - discursividade que julgávamos enfraquecida, pelo menos no âmbito do poder público, mas retomada com força e repetida à exaustão pelos governantes eleitos no pleito de 2018 - compõe a estratégia discursiva de produção de saberes sobre o índio. Estratégia que vem se repetindo desde os tempos de implantação do colonialismo e que, proferida com maior frequência e veemência nos períodos em que os conflitos agrários se intensificam, visa expropriar as terras e as conquistas mais recentes dos povos indígenas.

Junto a esta lógica que sustenta que os índios não trabalham, que recebem muito apoio do Estado, que têm muita terra, segue-se a argumentação de que índios não necessitam

INTERLETRAS, ISSN No 1807-1597. V. 9, Edição número 34. Outubro, 2021/ Março de 2022- p

Dossiê: Estudos de indigenismo, negritude e miscigenação: o (des)cobrimento, colonização e o agora(?) . 
de terras ou de que "existe muita terra para pouco índio". Sobre esta questão, Guerra (2010) chama a atenção para a naturalização dos latifúndios, pois enquanto o direito do índio à terra questionado, não se questiona a apropriação de grandes extensões de terra dos latifundiários. Há os que justificam que a terra do índio é ociosa, enquanto que a terra do latifundiário é utilizada para a produção... há ainda, no Brasil de hoje, os que afirmam que os "verdadeiros" latifundiários são os índios...

A defesa da disposição para o trabalho do indígena é recorrente, contrariando os já-ditos que (in)significam o índio e demarcando sua capacidade de atuação nos diferentes setores da vida humana. É dessa forma que interpretamos o recorte discursivo 5

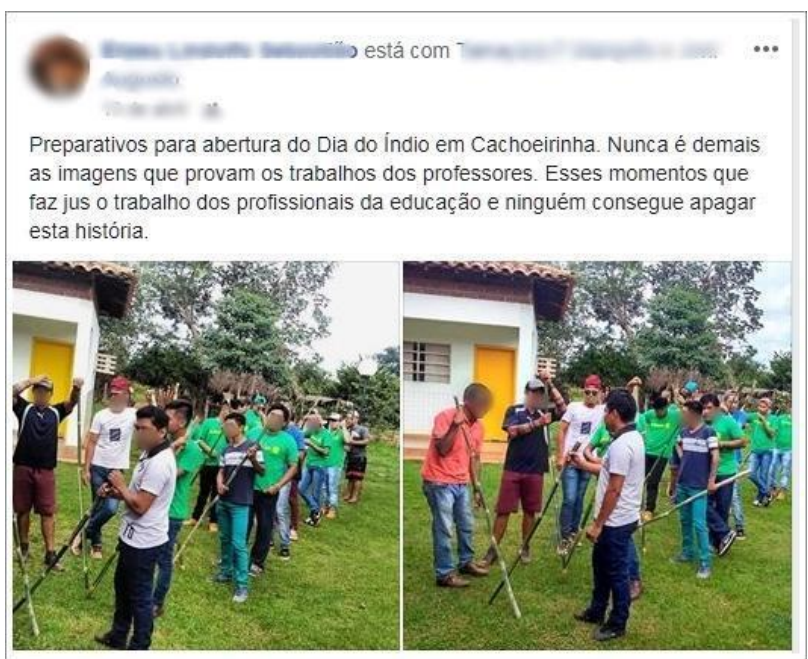

Recorte discursivo 5

A postagem apresenta imagens de alunos e professores preparando alguma apresentação para a comemoração do dia do índio. O enunciado destaca o trabalho dos professores e profissionais da educação. No enunciado "nunca é demais as imagens que provam os trabalhos dos professores", salientamos os itens "nunca é demais" e "provam" que retomam, via interdiscurso, a afirmação excessivamente repetida que afirma que o "índio não trabalha" ou que o "índio é preguiçoso". Assim, se a afirmação é repetida à exaustão, "nunca é demais" "combatê-la". Um dos sentidos de "provar", de acordo com o dicionário, é o de "demonstrar a verdade, a realidade, a autenticidade de (uma coisa) com razões, fatos etc." (HOUAISS, 2016).

Muito próximo desta acepção, em sentido jurídico, "provar" é "demonstrar a verdade formal dos fatos discutidos, mediante procedimentos determinados, ou seja, através de meios legais (legítimos)" (HOLTHAUSEN, 2008). "Provar", "fazer jus (fazer justiça)", vincula-se à formação discursiva jurídica em que o sujeito busca "comprovar" a verdade dos fatos com imagens, de forma a "contestar" e "anular" a afirmação de que o índio,

INTERLETRAS, ISSN No 1807-1597. V. 9, Edição número 34. Outubro, 2021/ Março de 2022- p

Dossiê: Estudos de indigenismo, negritude e miscigenação: o (des)cobrimento, colonização e o agora(?) . 
neste caso o professor índio, não trabalha. Afinal, quando se prova a verdade, a autenticidade dos fatos, não há mais o que discutir: a aqueles que dizem que o índio não trabalha, a aqueles que acusam o índio de ser preguiçoso, S5 estaria apresentando a "prova" contrária, "a realidade dos fatos".

Ao afirmar que "ninguém consegue apagar esta história" que está sendo comemorada, o sujeito vincula o presente ao passado, aos diferentes períodos da história, desde a expansão colonial, em que já se afirmava que o indígena não trabalha. Dessa forma, "provar" o trabalho do índio no presente é também reescrever um passado de trabalho e, portanto, de capacidade e aptidão que "ninguém pode apagar".

A afirmação da capacidade indígena em oposição à dificuldade ou falta de competência do branco em gerir instituições de políticas indigenistas, a defesa da importância da representação política nas câmaras municipais para a proteção de seus interesses, a defesa da capacidade de trabalho do indígena são ações que se opõem ao regime tutelar, considerando possibilidades de atuação que evocam a ideia de resistência e que expressam um posicionamento quanto aos lugares que o indígena deve ocupar na sociedade. Há, assim, uma discursividade de afirmação da identidade indígena como sujeitos de ações políticas, capazes de organização para a disputa de posições de poder e que, através da união com seus pares, elaboram suas próprias táticas no sentido de ocupar espaços, antes disponíveis apenas aos "purutuye", e, assim, exercerem seu protagonismo.

\section{Considerações finais}

A partir das análises realizadas, pudemos problematizar as práticas indígenas que se contrapõem à ordem dominante e ao projeto hegemônico de homogeneização. Confirmando nossa hipótese inicial - de que os sujeitos indígenas usam o Facebook para produzir deslocamentos aos discursos cristalizados sobre a identidade indígena - as ações estratégicas de ocupações dos espaços de poder antes destinados aos homens brancos, no ciberespaço inclusive, articulam-se para contrapor às estruturas de dominação, ao regime tutelar e às políticas indigenistas, em defesa dos interesses dos índios.

As ações ora questionam a ordem jurídica, ora se dão a partir de projetos coletivos, ora a partir de ações individuais ancoradas em decisões coletivas, tais como posicionar-se publicamente na rede social, produzindo deslocamentos de sentidos cristalizados sobre o indígena em nossa sociedade, confirmando nossa hipótese inicial de que os sujeitos indígenas usam o Facebook para produzir ressignificar sua história. Seja no enfrentamento político ou nas práticas cotidianas de resistência, há a afirmação da autonomia, da capacidade indígena de controlar sua própria vida e a contra identificação aos discursos de vitimização e incapacidade. Mais que isso, como destaca o indígena Machado (2019), os povos indígenas têm seus projetos de futuro não limitados à luta pela

INTERLETRAS, ISSN $N^{o}$ 1807-1597. V. 9, Edição número 34. Outubro, 2021/ Março de 2022- p

Dossiê: Estudos de indigenismo, negritude e miscigenação: o (des)cobrimento, colonização e o agora(?) . 
terra, mas reivindicando novos espaços, construindo novas territorialidades para a participação na construção da nação a qual fazem parte.

Tem-se assim um processo de constituição identitária que opera a partir de uma divisão entre as representações do outro sobre o que é ser indígena e a negação dessas representações para a construção de representações outras sobre o que é ser índio a partir de lógicas distintas da racionalidade ocidental. Distanciando-se da percepção hegemônica utilitarista de território como propriedade privada destinada à exploração humana e partindo de uma compreensão em que prevalece uma relação de comunhão com o território e com o seu entorno, o sujeito indígena constitui uma identidade marcada pela negação de estereótipos presentes no imaginário ocidental.

\section{REFERÊNCIAS}

AUTHIER-REVUZ, Jacqueline. Palavras incertas: as não-coincidências do dizer. Campinas, SP: Unicamp, 1998.

CARDOSO, Wanderley Dias. A história da educação escolar para o Terena: origem e desenvolvimento do ensino médio na aldeia Limão Verde. 2011. Tese (Doutorado em História). Pontifícia Universidade Católica, Porto Alegre, 2011.

BRASIL. Lei n. 3.071 de $1^{\circ}$ de janeiro de 1916. Código Civil dos Estados Unidos do Brasil. Disponível em:<http://www.planalto.gov.br/ccivil_03/leis/l3071.htm>. Acesso em 09 de maio de 2021.

CASTRO-GOMEZ, Santiago. Ciências Sociais, violência epistêmica e o problema da "invenção do outro". In: LANDER, Edgardo. (org). A colonialidade do saber: eurocentrismo e ciências sociais. Perspectivas latino-americanas. Buenos Aires: CLACSO, Ciudad Autónoma de Buenos Aires, 2005.

CORACINI, Maria José R.F. Identidade \& discurso:(des)construindo subjetividades. Campinas: Editora da UNICAMP, Chapecó: Argos, 2003.

CUNHA, Rodrigo Bastos. Políticas de línguas e educação escolar indígena no Brasil. Educ.Rev., n.32, 2008. p.143-159.

FERREIRA, Andrey Cordeiro. Tutela e resistência indígena: etnografia e história das relações de poder entre os Terena e o Estado Brasileiro. 2007. 413p. Tese. (Doutorado em Antropologia Social). Universidade Federal do Rio de Janeiro, Rio de Janeiro, 2007.

FOUCAULT, Michel. A arqueologia do saber. Rio de Janeiro, Forense Universitária, 2008.

INTERLETRAS, ISSN No 1807-1597. V. 9, Edição número 34. Outubro, 2021/ Março de 2022- p

Dossiê: Estudos de indigenismo, negritude e miscigenação: o (des)cobrimento, colonização e o agora(?) . 
GUERRA, Vânia M. L. O indígena de Mato Grosso do Sul: práticas identitárias e culturais. São Carlos: Pedro \& João Editores, 2010.

GUERRA, Vânia M. L. Povos indígenas: identidade e exclusão social. Campo Grande: Ed. UFMS, 2015.

HALL, Stuart.Quem precisa de identidade?In: SILVA,Tomaz Tadeu (Org.). Identidade e diferença: a perspectiva dos Estudos Culturais. Petrópolis: Vozes, 2000.

HALL, Stuart. A. A identidade cultural na pós-modernidade. Tradução Tomaz Tadeu da Silva. 4 ed. Rio de Janeiro: DP\&A, 2006.

HALL, Stuart. Sin garantías: Trayectorias y problemáticas en estudios culturales. Eduardo Restrepo, Catherine Walsh y Víctor Vich (eds.) Instituto de estudios sociales y culturales Pensar, Universidad Javeriana. Instituto de Estudios Peruanos, Universidad Andina Simón Bolívar, sede Ecuador, Envión Editores, 2010.

HOUAISS, Antônio. Dicionário Houaiss da Língua Portuguesa. Rio de. Janeiro: . Objetiva, 2016.

HOLTHAUSEN, Fábio Zabot. Prova judicial: conceito, origem, objeto, finalidade e destinatário. Âmbito Jurídico, Rio Grande, XI, n. 56, 2008. Disponível em: http://www.ambitojuridico.com.br/site/index.php?n_link=revista_artigos_leitura\&artigo _id=5 043. Acesso em 19 de jan. 2021.

LUCIANO, Gersem dos Santos. O Índio Brasileiro: o que você precisa saber sobre os povos indígenas no Brasil de hoje. Brasília: Ministério da Educação, Secretaria de Educação Continuada, Alfabetização e Diversidade; LACED/Museu Nacional, 2006.

MACHADO, Almires Martins . Terena, guarani, kaiowá e guateka: convivência entre nós e os outros. In: MOTA, Juliana Grasiéli Bueno; CAVALCANTE, Thiago Leandro Vieira (Orgs.)Reserva Indígena de Dourados: Histórias e Desafios Contemporâneos. Ebook, São Leopoldo: Karywa, 2019.

MIDIAMAX. 2016. Urnas deram mandato de vereador para 12 índios em MS este ano.Disponível em: https://www.midiamax.com.br/politica/2016/urnas-deram- mandato -de-vereador-para-12 -indios-em-ms-este-ano . Acesso em 12 de ago. de 2021.

NEVES, Maria Helena Moura. Gramática de usos do português. SP: Ed. UNESP, 2000.

PÊCHEUX, M. Semântica e discurso: uma crítica à afirmação do óbvio. Tradução de Eni P. Orlandi. Campinas: Editora da Unicamp, 1988.

INTERLETRAS, ISSN No 1807-1597. V. 9, Edição número 34. Outubro, 2021/ Março de 2022- p

Dossiê: Estudos de indigenismo, negritude e miscigenação: o (des)cobrimento, colonização e o agora(?) . 
QUIJANO, Anibal. Colonialidad y Modernidad-Racionalidad. In: BONILLA, Heraclio (Org.). Los conquistados: 1492 y la población indígena de las Américas. Santafé de Bogotá, Colombia: Tercer Mundo; Ecuador: FLACSO: Libri Mundi, 1992, p. 437-447.

QUIJANO, Anibal. Colonialidade do poder, eurocentrismo e América Latina. In:. A colonialidade do saber: eurocentrismo e ciências sociais. Perspectivas latino-americanas. Edgardo Lander (org). Colección Sur Sur, CLACSO, Ciudad Autónoma de Buenos Aires, Argentina. Setembro, 2005.

RESENDE, Ana Catarina Zema de. Direitos e autonomia indígena no Brasil (1960-2010): uma análise histórica à luz da teoria do sistema-mundo e do pensamento decolonial. 2014. 360f. Tese. (Doutorado em História) Universidade de Brasília, 2014.

SANTOS, Milton. A Natureza do Espaço - Técnica e Tempo. Razão e Emoção. São Paulo: Edusp, 2002.

VARGAS, Vera Lúcia Ferreira. A dimensão sociopolítica do território para os Terena: as aldeias nos séculos XX e XXI. 2011. 187f. Tese (Doutorado em História) - Universidade Federal Fluminense, Instituto de Ciências Humanas e Filosofia, 2011.

VEIGA-NETO, Alfredo. Foucault \& a educação. Belo Horizonte: Autêntica, 2003.

\footnotetext{
*Doutora em Letras da área de concentração em Estudos Linguísticos e da linha de pesquisa "Discurso, subjetividades e ensino de Línguas", pela Universidade Federal de Mato Grosso do Sul. https://orcid.org/0000-0001-7568-1195
}

INTERLETRAS, ISSN No 1807-1597. V. 9, Edição número 34. Outubro, 2021/ Março de 2022- p

Dossiê: Estudos de indigenismo, negritude e miscigenação: o (des)cobrimento, colonização e o agora(?) . 